|| ISSN(online): 2589-8698 || ISSN(print): 2589-868X || International Journal of Medical and Biomedical Studies

Available Online at www.ijmbs.info

Volume 3, Issue 2; February: 2019; Page No. 64-66

PubMed (National Library of Medicine ID: 101738825)

Index Copernicus Value 2017: 40.03

\title{
EVALUATION OF ANTIBIOTIC SENSITIVITY PATTERN IN ACUTE TONSILLITIS
}

\author{
Sadhana Joshi ${ }^{1}$, Gaurav Parashar ${ }^{2}$ \\ ${ }^{1}$ Senior Demonstrator Department of Microbiology, ${ }^{2}$ Senior Resident Department of ENT. \\ ${ }^{1-2}$ RVRS Medical College, Bhilwara
}

Article Info: Received 23 January 2019; Accepted 15 February. 2019

Cite this article as: Joshi, S., \& Parashar, G. (2019). EVALUATION OF ANTIBIOTIC SENSITIVITY PATTERN IN ACUTE TONSILLITIS. International Journal of Medical and Biomedical Studies, 3(2).

DOI: https://doi.org/10.32553/ijmbs.v3i2.97

Address for Correspondence: Gaurav Parashar, RVRS Medical College, Bhilwara

Conflict of interest: No conflict of interest.

\begin{abstract}
Background: Tonsillitis is a frequent condition noticed in the ENT department of every hospital. One out of every 10 children visiting the ENT OPD, suffer from acute tonsillitis.

Methods: This was a prospective observational study conducted on patients coming with a history of throat pain, pain on swallowing, fever, body ache and other constitutional symptoms.

Results: Antibiotic resistance was seen in case of the commonly used antibiotics like ampicillin, amoxicillin, Amoxicillin+Clavulanic acid. Cephalosporins were less commonly used antibiotics and showed resistance in $78.00 \%$ cases. Cotrimoxazole showed about $16.00 \%$ resistant cases. The less commonly used antibiotic was vancomycin however, showed high sensitivity (100\%) followed by Linezolid (92.00\%) and Clindamycin (82.00\%). Erythromycin showed $76 \%$ sensitivity while ciprofloxacin showed a low sensitivity of $40.00 \%$ followed by Cephalosporins $(22.0 \%)$.

Conclusion: The antibiotic sensitivity pattern could revolutionize the management of chronic tonsillitis.
\end{abstract}

Keywords: Acute tonsillitis, Antibiotics, Sensitivity

\section{Introduction:}

Tonsillitis is a frequent condition noticed in the ENT department of every hospital. One out of every 10 children visiting the ENT OPD, suffer from acute tonsillitis. ${ }^{1}$ It occurs when the trapped organisms infiltrate the mucosal barrier and attribute themselves to the epithelial cells, leading to cytokine production and complement activation. These series of reactions produce an inflammatory reaction in the tonsillar mucosa. ${ }^{2}$ Staphylococci and beta haemolytic Streptococci are the major organisms involved in the pathogenesis acute tonsillitis. Other pathogens involved are Group A beta haemolytic Streptococci, Klebsiella pneumoniae, E. coli. ${ }^{3}$
The use of antibiotics against these bacteria has been the general trend through the years. Penicillin has been the drug of choice for acute tonsillitis. Other antibiotics preferred in penicillin allergic cases include are Cephalosporin, macrolides, erythromycin and tetracycline's etc. ${ }^{4}$

However, over the years, there has been an emerging trend of resistance to these antibiotics among the bacteria. Recent studies have shown biofilms as one of the causes. ${ }^{5}$ While some bacteria have managed to develop resistant enzymes like beta lactamase, some others have mechanisms that pump out the antibiotic. Since bacteria had developed a beta lactamase enzyme that degrades the beta lactam ring of antibiotics, beta lactamase resistant antibiotics were 
developed. These antibiotics like Amoxicillin+Clavulanic acid have proved to be useful in the treatment of tonsillitis to a great extent. But, recent studies are showing an increasing resistance to these antibiotics too.

\section{Methods}

This was a prospective observational study.

\section{Inclusion criteria}

Inclusion criteria were patients coming with a history of throat pain, pain on swallowing, fever, body ache and other constitutional symptoms. Patients with a clinical evidence of acute tonsillitis which includes congestion over the anterior pillar, redness of the tonsils, enlarged and tender jugulo-digastric lymph nodes.

Exclusion criteria

Patients with HIV/Immune compromised patients, diabetes, patients on steroid medications, patients with a history of chronic granular pharyngitis and patient belonging to an age group of more than 50 years were excluded from the study.

\section{RESULTS}

Table 1: Resistance and sensitivity observed against various antibiotics.

\begin{tabular}{|l|l|l|}
\hline Antibiotic & Resistance & Sensitive \\
\hline Methicillin & $60.00 \%$ & $40.00 \%$ \\
\hline Gentamicin & $14.00 \%$ & $86.00 \%$ \\
\hline Vancomycin & $0.00 \%$ & $100.00 \%$ \\
\hline Erythromycin & $24.00 \%$ & $76.00 \%$ \\
\hline Ciprofloxacin & $60.00 \%$ & $40.00 \%$ \\
\hline Cotrimoxazole & $16.00 \%$ & $84.00 \%$ \\
\hline Ofloxacin & $64.00 \%$ & $36.00 \%$ \\
\hline Clindamycin & $18.00 \%$ & $82.00 \%$ \\
\hline Linezolid & $8.00 \%$ & $92.00 \%$ \\
\hline Ampicillin & $58.00 \%$ & $42.00 \%$ \\
\hline Amoxycillin & $56.00 \%$ & $44.00 \%$ \\
\hline Amoxycillin+clavulanate & $74.00 \%$ & $26.00 \%$ \\
\hline Amikacin & $28.00 \%$ & $72.00 \%$ \\
\hline Norfloxacin & $0.00 \%$ & $100.00 \%$ \\
\hline Cephalexin & $78.00 \%$ & $22.00 \%$ \\
\hline Cefotaxime & $78.00 \%$ & $22.00 \%$ \\
\hline
\end{tabular}

Antibiotic resistance was seen in case of the commonly used antibiotics like ampicillin, amoxicillin, Amoxicillin+Clavulanic acid. Cephalosporins were less commonly used antibiotics and showed resistance in $78.00 \%$ cases. Cotrimoxazole showed about $16.00 \%$ resistant cases. The less commonly used antibiotic was vancomycin however, showed high sensitivity (100\%) followed by Linezolid (92.00\%) and Clindamycin (82.00\%). Erythromycin showed $76 \%$ sensitivity while ciprofloxacin showed a low sensitivity of $40.00 \%$ followed by Cephalosporins (22.0\%).

\section{Discussion}

In our study antibiotic resistance was seen in case of the commonly used antibiotics like ampicillin, amoxicillin, Amoxicillin+Clavulanic acid. Cephalosporins were less commonly used antibiotics and showed resistance in $78.00 \%$ cases. Cotrimoxazole showed about $16.00 \%$ resistant cases. The less commonly used antibiotic was vancomycin however, showed high sensitivity (100\%) followed by Linezolid 
(92.00\%) and Clindamycin (82.00\%). Erythromycin showed $76 \%$ sensitivity while ciprofloxacin showed a low sensitivity of $40.00 \%$ followed by Cephalosporins (22.0\%). This was found to be in accordance with the findings of Tsering in $2011 .{ }^{6}$ The high sensitivity of vancomycin may be due to its mechanism of inhibiting cell wall synthesis by binding to the building blocks of peptidoglycan wall of the bacteria. Also, vancomycin is the final resort used in case the other antibiotics fail. This may also be a cause of its high sensitivity pattern.

\section{Conclusion}

The antibiotic sensitivity pattern could revolutionize the management of chronic tonsillitis.

\section{References}

1. Babaiwa UF, Onyeagwara NC, Akerele JO. Bacterial tonsillar microbiota and antibiogram in recurrent tonsillitis.
Biomedical Research of India. 2013;24 (3): 298-302.

2. Alexander EH, Hudson MC.Factors influencing the internalization of Staphylococcus aureus and impacts on the course of infections in humans. Applied Microbiol Biotechnol. 2001;56(3-4):361-6.

3. Jayasimha VL, Vinod Kumar CS, Raghukumar KG, Basavarajappa. Surface Tonsillar bacteria versusa deep tonsillar bacteria in tonsillitis. J Public Health Res. 2013;1(2):92-4.

4. Kaufman J. Antibiotics to Treat Tonsillitis. Available at: https://www.livestrong.com/ article/ 164743-antibiotics-to-treat-tonsillitis /. Accessed on 14 January 2018.

5. Chole RA, Faddis BT. Anatomical Evidence of Microbial biofilms in tonsillar tissues. Arch Otolaryngology Head Neck Surg. 2003;129(6):634- 6

6. Tsering DC, Pal R, Karl S. MethicillinResistant Staphylococcus aureus: Prevalence and Current Susceptibility Pattern in Sikkim. J Global Infectious Dis. 2011;3(1):9-13. 